https://doi.org/10.31533/pubvet.v14n8a646.1-5

\title{
Determinação da concentração plasmática de cTSH no diagnóstico de hipotireoidismo primário em cães: Relato de quatro casos
}

\author{
Thalita de Freitas Durval $^{1 *}$, Renata Novais Mencalha $^{2 \bullet}$, Fabrício Nascimento Gaudêncio ${ }^{3 \bullet}$ \\ ${ }^{I}$ Discente do Curso de Graduação em Medicina Veterinária-Universidade Fundação Educacional Dom André Arcoverde -UNIFAA, Valença, \\ Rio de Janeiro, Brasil. \\ ${ }^{2}$ Médica veterinária autônoma, Acre, Brasil. \\ ${ }^{3}$ Docente do Curso de Graduação em Medicina Veterinária-UNIFAA, Valença, Rio de Janeiro, Brasil. \\ *Autor para correspondência, E-mail: thalitaveterinaria@yahoo.com.br
}

\begin{abstract}
Resumo. O hipotireoidismo primário em cães apresenta sinais clínicos inespecíficos e sistêmicos, o que impossibilita o diagnóstico somente através de exame clínico, hemograma e bioquímica sérica de rotina. Dessa forma, deve-se realizar testes de função da tireoide aliados aos sinais clínicos, para o diagnóstico definitivo desta endocrinopatia. Quatro cães, um macho e três fêmeas, com idade entre 4 e 10 anos, que apresentavam sinais clínicos sugestivos de hipotireoidismo foram avaliados quanto às concentrações plasmáticas de T4 livre (fT4) e TSH canino (cTSH). Em todos os cães diagnosticados com hipotireoidismo primário, observou-se aumento da concentração de cTSH e diminuição do T4 livre. À medida que foram tratados com levotiroxina sódica, observou-se melhora na reavaliação dos parâmetros de cTSH e fT4. Hemograma e bioquímica sérica foram realizados para auxiliar no descarte das comorbidades e eutireoideo doente. $\mathrm{O}$ diagnóstico definitivo e acompanhamento do tratamento do hipotireoidismo primário deve se basear nas determinações das concentrações plasmáticas de fT4 e cTSH. Recomenda-se descartar o quadro de eutireoideo doente para o sucesso da terapia de reposição hormonal.
\end{abstract}

Palavras chave: endocrinopatia, hipotireoidismo canino, tiroxina

\section{Determination of cTSH plasmatic concentration in diagnosis of primary hypothyroidism in dogs: case report}

\begin{abstract}
Primary hypothyroidism in dogs presents nonspecific and systemic clinical signs, which precludes diagnosis only through clinical examination, blood count and routine serum biochemistry. Thus, thyroid function tests, together with clinical signs, should be performed for the definitive diagnosis of this endocrinopathy. Four dogs, one male and three females, aged 4 to 10 years, with clinical signs suggestive of hypothyroidism were evaluated for free T4 (fT4) and canine TSH (cTSH) plasma concentrations. In all dogs diagnosed with primary hypothyroidism, an increase was observed. cTSH concentration and free T4 decrease. As they were treated with sodium levothyroxine, there was an improvement in the reevaluation of TSH and fT4 parameters. Blood count and serum biochemistry were performed to help to rule out comorbidities and diseased euthyroid. Definitive diagnosis and follow-up of primary hypothyroidism treatment should be based on determinations of fT4 and cTSH plasma concentrations. It is recommended to rule out the sick euthyroid condition for successful hormone replacement therapy.
\end{abstract}

Keywords: canine hypothyroidism, endocrinopathy, thyroxine 


\title{
Determinación de la concentración plasmática de cTSH en el diagnóstico de hipotiroidismo primario en perros: Informe de cuatro casos
}

\begin{abstract}
Resumen: El hipotiroidismo primario en perros presenta signos clínicos inespecíficos y sistémicos, lo que impide el diagnóstico solo mediante examen clínico, recuento sanguíneo y bioquímica sérica de rutina. Por lo tanto, se deben realizar pruebas de función tiroidea, junto con signos clínicos, para el diagnóstico definitivo de esta endocrinopatía. Cuatro perros, un macho y tres hembras, de 4 a 10 años, con signos clínicos que sugieren hipotiroidismo se evaluaron para determinar las concentraciones plasmáticas de T4 (fT4) libre y cTSH. En todos los perros diagnosticados con hipotiroidismo primario, hubo un aumento de la concentración de cTSH y la disminución de T4 libre. Como fueron tratados con levotiroxina de sodio, hubo una mejora en la reevaluación de los parámetros TSH y fT4. Se realizaron recuentos sanguíneos y bioquímica sérica para ayudar a descartar comorbilidades y eutiroides enfermos. El diagnóstico definitivo y el seguimiento del tratamiento primario de hipotiroidismo deben basarse en determinaciones de las concentraciones plasmáticas de fT4 y cTSH. Se recomienda descartar la enfermedad eutiroidea enferma para una terapia de reemplazo hormonal exitosa.
\end{abstract}

Palabras clave: endocrinopatía, hipotiroidismo canino, tiroxina

\section{Introdução}

A insuficiência na produção e/ou secreção dos hormônios tireoidianos é conhecida como hipotireoidismo (Kahn et al., 2005). Esta endocrinopatia pode decorrer da destruição progressiva da tireoide e, geralmente tem como etiologia a tireoidite linfocítica, uma destruição imunomediada da glândula. Como consequência, observa-se substituição do parênquima glandular por tecido conjuntivo fibroso (Nelson \& Couto, 2015; Peterson, 2007).

Normalmente, a doença acomete cães com idade entre 4 a 10 anos, sendo os sinais clínicos mais precoces nas raças de risco, como Golden Retriever, Doberman, Pincher, Dachshund, Setter Irlandês, Schanauzer Miniatura, Dogue Alemão, Poodle e Boxer. Presume-se que não exista predileção sexual, embora a castração seja considerada um fator predisponente em função do efeito dos hormônios sexuais no sistema imune, principalmente em fêmeas, elevando a severidade da tireoidite autoimune (Mello, 2004).

O diagnóstico clínico do hipotireoidismo pode ser difícil em função das diversas formas que a doença pode se apresentar clinicamente: alterações dermatológicas, neuromusculares, reprodutivas e cardiovasculares (Ettinger et al., 2002). A alopecia de tronco é predominante em algumas raças, e o adelgaçamento da pele, em outras. A alopecia pode ser localizada (envolvendo apenas a cauda, por exemplo, a "cauda de rato"), ou generalizada e, geralmente, inicia-se nos locais de maior fricção. A seborreia e a piodermite também são alterações comuns podendo ser focais, multifocais ou generalizadas. Todas as formas de seborreia (seca, oleosa ou mista) são possíveis (Nelson \& Couto, 2015; Peterson, 2007). Letargia, ganho de peso, indisposição ao exercício e intolerância ao frio derivam da diminuição da taxa metabólica (Ettinger et al., 2002).

Uma condição que pode levar à uma situação clinicamente semelhante ao hipotireoidismo é o paciente eutireoideo doente. Ele possui a tireoide preservada, ou seja, sem doença (eutireoideo), mas apresenta T4 típico de paciente hipotireoideo (Carvalho, 2017).

A concentração basal de TSH canino plasmático (cTSH) é um teste confirmatório e tem uma especificidade de $98 \%$ quando é usado juntamente com os testes da avaliação de T4 total (T4T) ou os níveis de T4 livre por diálise (fT4) (Finora \& Greco, 2007). A mensuração de uma concentração aumentada do cTSH é específica para o diagnóstico de hipotireoidismo primário se a T4T ou fT4 estiverem reduzidas (Ettinger et al., 2002).

O presente trabalho teve como objetivo ressaltar a importância da dosagem hormonal de TSH para o diagnóstico de hipotireoidismo primário em cães que apresentam sinais clínicos sugestivos da endocrinopatia. 


\section{Relato de caso}

Foram atendidos na Policlínica Veterinária Escola da UNIFAA em Valença- RJ, quatro cães de raças variadas (Tabela 1), com idades entre 4 a 10 anos. Os sinais clínicos comuns apresentados por todos os pacientes era dermatopatia com infecções por bactérias (cocos) ou leveduras (Malassezia sp.) e ganho de peso. A pesquisa pela causa de base das dermatopatias é que gerou a suspeita de hipotireoidismo. Outro sinal clínico observado comum aos quatro animais foi o sobrepeso (Figura 1A).

Tabela 1. Identificação dos pacientes e principais sinais clínicos relatados pelos tutores e observados ao exame clínico.

\begin{tabular}{llll}
\hline Paciente & Idade & Raça & Sinais clínicos \\
\hline Animal 1 & 4 anos & Beagle & Mixedema facial discreto, leucotriquia e descamação no dorso discretas e sobrepeso \\
Animal 2 & 6 anos & SRD & Dermatite bacteriana e alérgica desde 5 anos de idade, sobrepeso \\
Animal 3 & 5 anos & Maltês & Prostração, dermatite alérgica e sobrepeso \\
Animal 4 & 10 anos & Labrador & Dermatite bacteriana e sobrepeso \\
\hline
\end{tabular}

SRD (sem raça definida).

O diagnóstico de hipotireoidismo primário foi obtido através da aferição da concentração plasmática de fT4 inferior ao valor de referência e concentração de cTSH plasmático superior ao limite de referência (Tabela 2).

Tabela 2. Resultados de dosagens séricas de T4 livre (fT4) por diálise (ng/mL) e cTSH (ng/mL) dos cães diagnosticados com hipotireoidismo primário (intervalo de referência utilizado pelo laboratório: TSH: 0,01 a 0,58 ng/mL e fT4: 0,70 a 3,03 ng/mL).

\begin{tabular}{lcc}
\hline Paciente & fT4 (ng/mL) & $\mathrm{cTSH}(\mathrm{ng} / \mathrm{mL})$ \\
\hline Animal 1 & 0,17 & 2,03 \\
Animal 2 & 0,67 & 1,50 \\
Animal 3 & 0,67 & 1,19 \\
Animal 4 & 0,58 & 1,12 \\
\hline
\end{tabular}

O tratamento instituído a todos os cães foi a levotiroxina sódica. Como o nível plasmático de fT4 varia entre os pacientes, deve-se proporcionalmente variar a dose prescrita aos animais com base na concentração plasmática do hormônio e a resposta clínica do paciente à terapia.

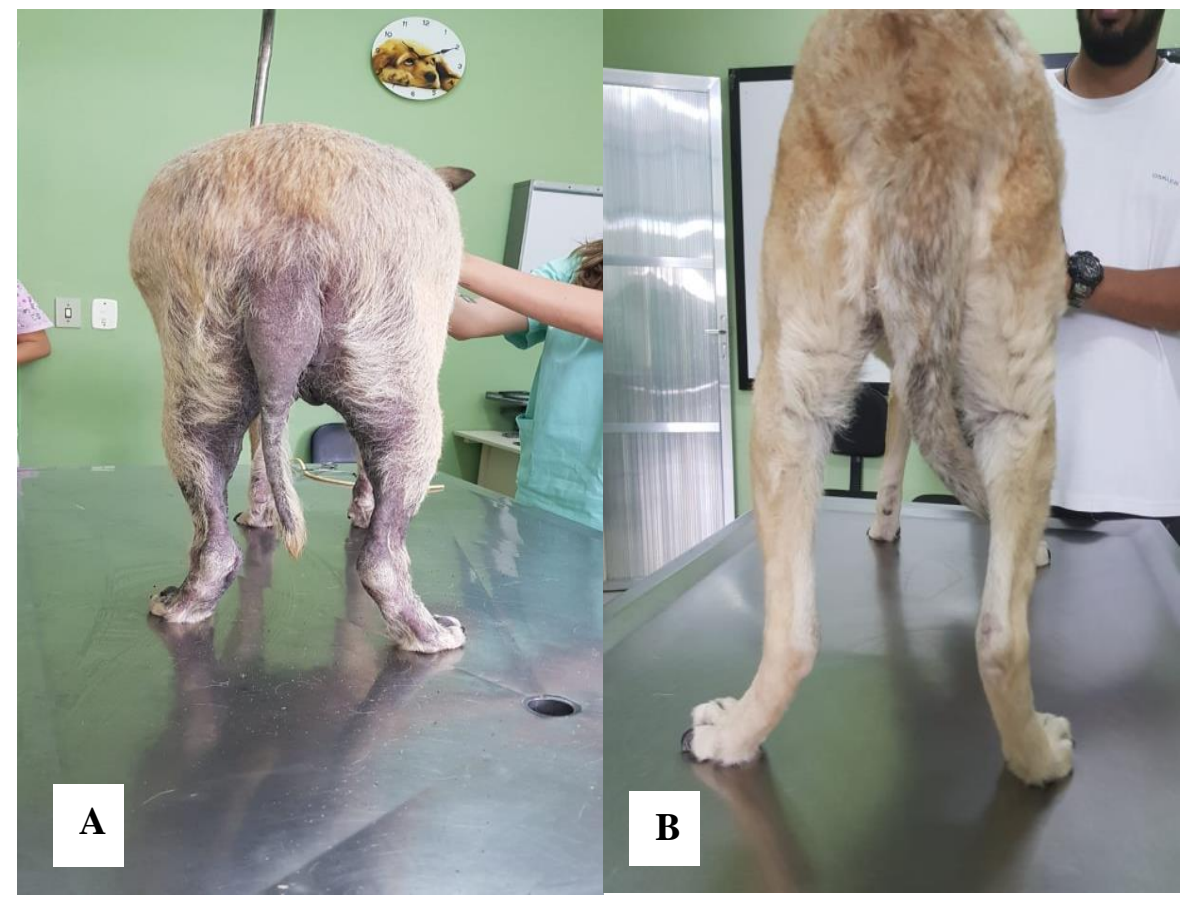

Figura 1. (A) Sinal clínico de "cauda-de-rato" na primeira consulta do animal 2 antes da confirmação de hipotireoidismo através das dosagens hormonais. (B) Mesmo animal em outra consulta já em tratamento. 


\section{Resultados e discussão}

O sucesso do tratamento dos animais avaliados no presente estudo foi obtido mediante monitoração terapêutica por testes da função da tireoide ou por observação da remissão dos sinais clínicos observados, como mostrado na figura 1B. Finora \& Greco (2007) relataram a importância da reavaliação dos animais quanto à função da tireoide a fim de verificar a eficácia do tratamento.

Dos quatro pacientes avaliados, em um deles foram repetidos os exames de dosagem de fT4 e cTSH após duas semanas de tratamento. Mediante esta reavaliação, constatou-se ter havido normalização das concentrações dos hormônios segundo os limites de referência do laboratório (animal 3: cTSH: 0,43 $\mathrm{ng} / \mathrm{mL}$; fT4: $1,55 \mathrm{ng} / \mathrm{mL}$ ).

Panciera et al. (2003) relataram que é possível observar resposta satisfatória do tratamento com duas semanas de uso da levotiroxina sódica. Com isso, a maioria das manifestações clínicas é resolvida como resposta à suplementação com hormônio da tireoide (Ettinger et al., 2002). No presente estudo, observou-se melhora clínica dos pacientes tratados e reavaliados quanto a concentração dos hormônios.

Nos animais 2 e 3 foram realizados exames complementares como hemograma e bioquímica sérica, a fim de descartar comorbidades que cursariam com o quadro de eutireoideo doente. No animal 2, observou-se anemia normocítica normocrômica. Este tipo, ainda que possua outras etiologias, é comumente observado nos casos de hipotireoidismo, pois os hormônios da tiroide estimulam a atividade e secreção da eritropoietina (Dixon et al., 1999; Graham et al., 2007; Héripret, 2008; Yamamoto et al., 2013).

No exame de bioquímica sérica, os animais 2 e 3 apresentaram aumentos da atividade sérica de ALT (112 U/L e 141U/L, respectivamente; intervalo de referência do laboratório: 5,0 a 75,0 U/L). Estes achados podem ser associados a possibilidade de acúmulo lipídico no fígado em função da alteração metabólica (Nelson \& Couto, 2015).

Nos pacientes 1, 2 e 3 foram realizados os testes de supressão com baixa dose de dexametasona para descartar hiperadrenocorticismo, uma endocrinopatia que, pelo excesso de corticoide endógeno, pode cursar com menor concentração plasmática de fT4 (Cunningham, 2011). Em todos os animais avaliados por este teste dinâmico endócrino, o diagnóstico foi negativo para hiperadrenocorticismo, o que auxiliou para descartar eutireoideo doente nestes pacientes.

Mediante tratamento apropriado, o hipotireoidismo pode ser controlado e ter um prognóstico excelente (Finora \& Greco, 2007). Contudo, vale ressaltar que o prognóstico sempre dependerá da causa subjacente, mas a expectativa de vida de um cão adulto diagnosticado com hipotireoidismo primário, quando submetido a tratamento adequado, normalmente não é afetada em função da doença.

\section{Conclusão}

Com base no presente relato, foi possível concluir que, para o estabelecimento do diagnóstico definitivo e melhor acompanhamento do tratamento de cães com hipotireoidismo primário deve-se utilizar as concentrações plasmáticas de cTSH e fT4 e que outros exames devem ser realizados a fim de descartar enfermidades concomitantes que cursem com o quadro de eutireoideo doente.

\section{Reconhecimentos}

Este estudo foi integralmente apoiado pela Centro de Ensino Superior de Valença - UNIFAA.

\section{Referências bibliográficas}

Carvalho, R. R. N. (2017). Avaliação do status funcional da Glândula Tireoide comparado com parâmetros hematológicos, bioquímicos, histológicos e moleculares na pele de cães da raça Golden Retriever. Universidade Federal Rural do Rio de Janeiro.

Cunningham, J. (2011). Tratado de fisiologia veterinária. Guanabara Koogan.

Dixon, M., Reid, S. W. J., \& Mooney, C. T. (1999). Epidemiological, clinical, haematological and biochemical characteristics of canine hypothyroidism. Veterinary Record, 145(17), 481-487. DOI: https://doi.org/10.1136/vr.145.17.481

Ettinger, S. J., Fedlman, E. C., \& Taibo, R. A. (2002). Tratado de medicina interna veterinaria: 
enfermedades del perro y el gato. Manole.

Finora, K., \& Greco, D. (2007). Hypothyroidism and myxedema coma. The Compendium on Continuing Education for the Practicing Veterinarian, 29(1), 19-32.

Graham, P. A., Refsal, K. R., \& Nachreiner, R. F. (2007). Etiopathologic findings of canine hypothyroidism. Veterinary Clinics of North America: Small Animal Practice, 37(4), 617-631. DOI: https://doi.org/10.1016/j.cvsm.2007.05.002

Héripret, D. (2008). Hypothyroidism. In E. Guaguére, P. Prélaud, \& M. Craig (Eds.), A pratical guide in canine dermatology (pp. 351-359). Merial, Kaliantis.

Kahn, C. M., Line, S., \& Aiello, S. E. (2005). The merck veterinary manual. Merck \& Co. Whitehouse Station.

Mello, F. P. D. S. (2004). Transtornos da glândula tireóide. Universidade Federal do Rio Grande do Sul.

Nelson, R. W., \& Couto, C. G. (2015). Medicina interna de pequenos animais (Issue 1). Elsevier Editora.

Panciera, D. L., Peterson, M. E., \& Birchard, S. J. (2003). Doenças tireoideanas. In S. J. Birchard \& R. G. Sherding (Eds.), Manual Saunders: Clínica de pequenos animias (pp. 261-264). Roca, Brasil.

Peterson, M. E. (2007). Diagnosis of hyperadrenocorticism in dogs. Clinical Techniques in Small Animal Practice, 22(1), 2-11. DOI: https://doi.org/10.1053/j.ctsap.2007.02.007

Yamamoto, S., Hoshi, K., Hirakawa, A., Chimura, S., Kobayashi, M., \& Machida, N. (2013). Epidemiological, clinical and pathological features of primary cardiac hemangiosarcoma in dogs: a review of 51 cases. Journal of Veterinary Medical Science, 75(11), 1433-1441. DOI: https://doi.org/10.1292/jvms.13-0064

Recebido: 27, de abril, 2020.

Aprovado: 30 de julho, 2020.

Disponível online: 10 de setembro, 2020.

Licenciamento: Este artigo é publicado na modalidade Acesso Aberto sob a licença Creative Commons Atribuição 4.0 (CC-BY 4.0), a qual permite uso irrestrito, distribuição, reprodução em qualquer meio, desde que o autor e a fonte sejam devidamente creditados. 